07.2

\title{
Обнаружение термовольтаического эффекта в гетероструктуре на основе теллурида свинца
}

\author{
(C) В.В. Каминскийㄹ, С.М. Соловьёв ${ }^{1}$, Н.М. Судакㄹ, М.И. Залдастанишвили ${ }^{2}$ \\ ${ }^{1}$ Физико-технический институт им. А.Ф. Иоффе РАН, Санкт-Петербург, Россия \\ ${ }^{2}$ Сухумский фризико-технический институт АН Абхазии, Сухум, Абхазия \\ E-mail: vladimir.kaminski@mail.ioffe.ru
}

Поступило в Редакцию 11 апреля 2019г.

В окончательной редакции 9 октября 2019г.

Принято к публикации 9 октября 2019г.

\begin{abstract}
Обнаружен термовольтаический эффект в гетероструктуре на основе полупроводникового материала, применяемого в термоэлектрических преобразователях в среднетемпературном диапазоне (PbTe). При постоянной температуре $T=390 \mathrm{~K}$ величина генерируемого напряжения составила $\sim 0.015 \mathrm{~V}$. При $T=732 \mathrm{~K}$ она составила $0.11 \mathrm{~V}$.
\end{abstract}

Ключевые слова: термовольтаический эффект, теллурид свинца, термоэдс, эффект Зеебека, термоэлектропреобразователь.

DOI: 10.21883/PJTF.2020.01.48866.17834

Актуальность поисков новых принципов преобразования различных видов энергий, в частности преобразования тепловой энергии в электрическую, определяется общей тенденцией перехода к экологически чистой и ресурсосберегающей энергетике. В 1999 г. при исследовании электрических свойств сульфида самария $(\mathrm{SmS})$ был обнаружен новый эффект, заключающийся в генерации образцом при однородном его нагреве до $T \sim 375-405 \mathrm{~K}$ электродвижущей силы, достигавшей в отдельных экспериментах величины $2.5 \mathrm{~V}$ в импульсе длительностью $1.3 \mathrm{~s}$ и $0.05 \mathrm{~V}$ в непрерывном режиме [1]. Впоследствии этот эффект был назван термовольтаическим, он обнаружен также на других полупроводниках: $\mathrm{ZnO}$ [2], Ge, Si [3] и различных полупроводниках сложного состава. В результате проведенных в 2012 г. прямых экспериментов по определению КПД преобразования тепловой энергии в электрическую на основе термовольтаического эффекта были получены величины до 28\% [4]. Впоследствии были достигнуты величины КПД до 36\%. Исследования показали, что природа эффекта связана с изменением валентности дефектных ионов самария, находящихся в вакансиях подрешетки серы: $\mathrm{Sm}^{2+} \rightarrow \mathrm{Sm}^{3+}+e^{-}$. При этом электроны с $4 f$-оболочки переходят в зону проводимости и создаются большие локальные концентрации носителей заряда. Эффект генерации электродвижущей силы в $\mathrm{SmS}$ наблюдается до $T \sim 470 \mathrm{~K}$. При более высоких температурах происходит истощение примесных донорных уровней с $E_{i} \sim 0.04 \mathrm{eV}$, градиент концентрации которых по объему образца вызывает наличие термовольтаического эффекта. Для практических приложений важным является переход в среднетемпературную область (700-1000 K).

$\mathrm{B}$ настоящей работе предпринята попытка обнаружения термовольтаического эффекта в полупроводниковом материале, применяемом для среднетемпературно- го интервала (теллуриде свинца $n$-типа, легированном иодистым свинцом [5]), с целью его дальнейшего исследования для выявления возможности применения в термоэлектропреобразователях, работающих на основе термовольтаического эффекта.

Для проведения экспериментов был изготовлен трехслойный образец из $\mathrm{PbTe} n$-типа диаметром $25 \mathrm{~mm}$ и общей толщиной $2.5 \mathrm{~mm}$. Слои имели примерно одинаковую толщину $\sim 0.8 \mathrm{~mm}$. Состав материала слоев был следующим. Первый слой - $\mathrm{PbTe}+0.065 \mathrm{~mol} . \%$ $\mathrm{PbI}_{2}+1.5$ wt.\% $\mathrm{Pb} ; \quad$ второй (средний) слой $\mathrm{PbTe}+0.04$ mol.\% $\mathrm{PbI}_{2}+1.5$ wt.\% $\mathrm{Pb}$; третий слой $\mathrm{PbTe}+0.016$ mol.\% $\quad \mathrm{PbI}_{2}+1.5$ wt.\% Pb. Коэффициенты термоэдс слоев при $T=300 \mathrm{~K}$ составляли соответственно $\alpha_{1}=70 \mu \mathrm{V} / \mathrm{K}, \alpha_{2}=120 \mu \mathrm{V} / \mathrm{K}, \alpha_{3}=150 \mu \mathrm{V} / \mathrm{K}$. Постепенное изменение величины термоэдс по толщине трехслойного образца указывает на наличие градиента концентрации примесных донорных уровней, который необходим для возникновения термовольтаического эффекта. Этот градиент задается различным количеством $\mathrm{PbI}_{2}$ в слоях. Образцы готовились посредством вакуумного прессования в течение $18-20$ min при температуре $750 \pm 10^{\circ} \mathrm{C}$ и давлении $27.5 \pm 1 \mathrm{MPa}$. Подъем температуры имел ступенчатый характер со ступенями по $\sim 2$ min при $T=450,550,650^{\circ} \mathrm{C}$ при увеличении давления от 0 до $27 \mathrm{MPa}$.

Измерение термовольтаического эффекта проводилось на установке, схематически представленной на рис. 1. Температура нагревателя 1 линейно повышалась до $T=150^{\circ} \mathrm{C}$ и удерживалась в течение заданного времени. Питание нагревателя осуществлялось блоком питания Voltcraft PPS-11815 (на рисунке обозначен $D 1$ ). Температура нагревателя контролировалась термопарой $T 2$, ее показания снимались мультиметром UNIT UT804 (D2). Затем питание нагревателя выключа- 


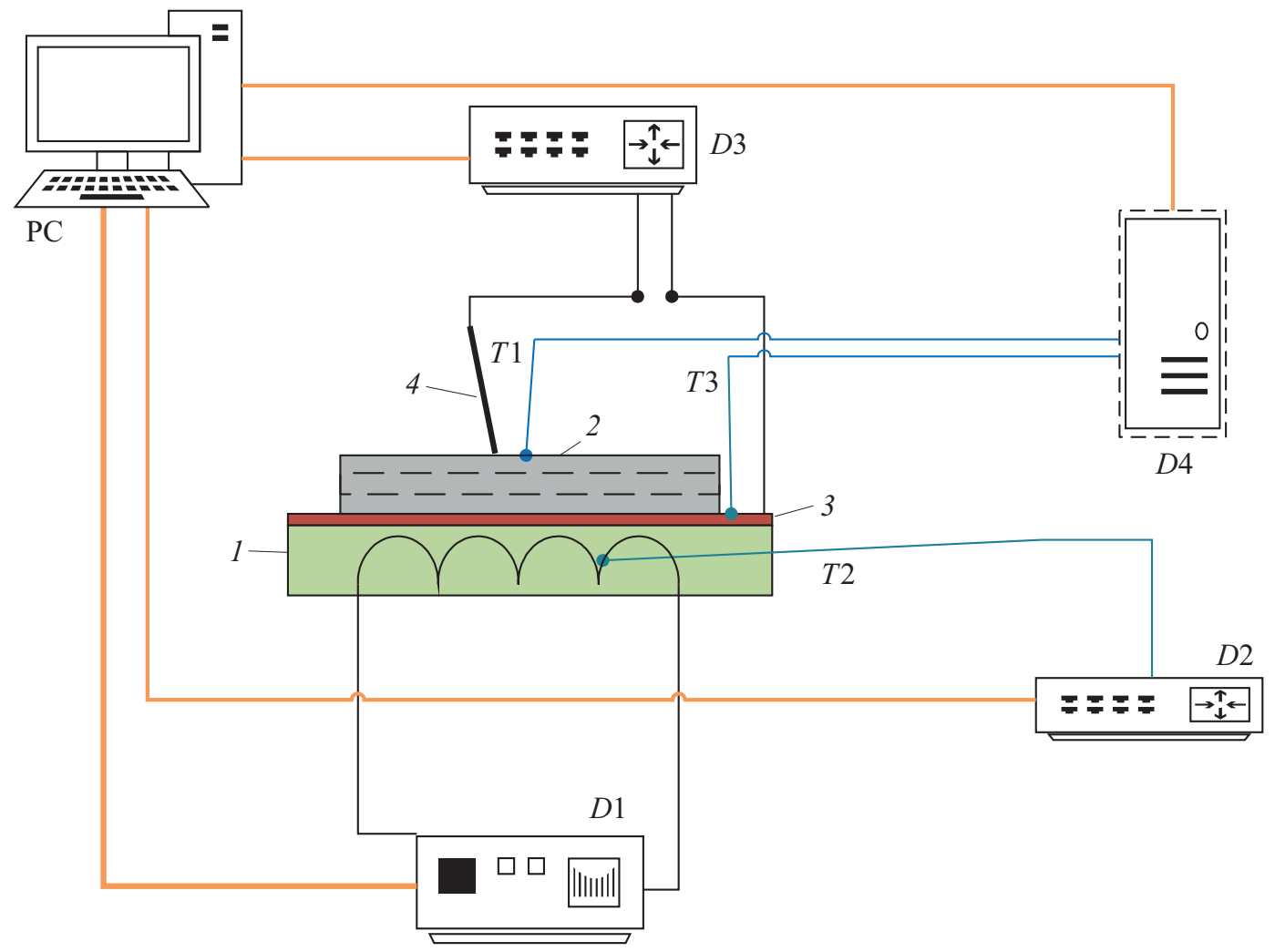

Рис. 1. Схема эксперимента. Пояснение в тексте.

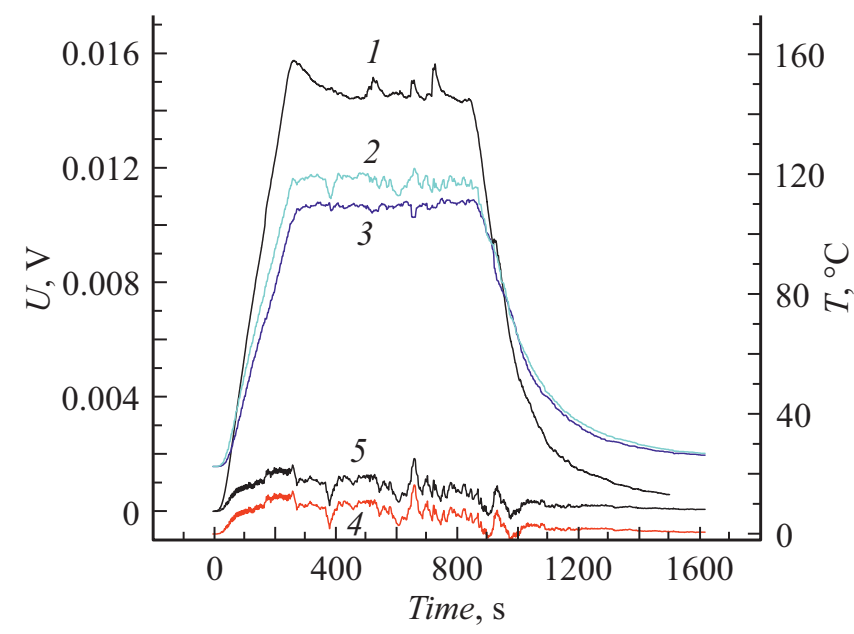

Рис. 2. Результаты эксперимента по измерению термовольтаического эффекта в гетероструктуре на основе $\mathrm{PbTe}$. 1 - выходной сигнал с образца; 2 - температура поверхности образца, прилегающей к нагревателю; 3 - температура противоположной поверхности образца; $4-$ временна́я зависимость разницы температур поверхностей образца $\Delta T$, на которых измеряется выходной сигнал; $5-$ составляющая выходного сигнала, получающаяся за счет эффекта Зеебека в образце, равная $U_{S} \approx \Delta T\left(\alpha_{1}+\alpha_{2}+\alpha_{3}\right) / 3$.

лось и остывание происходило естественным образом. Выходной сигнал с образца 2 снимался с нижнего

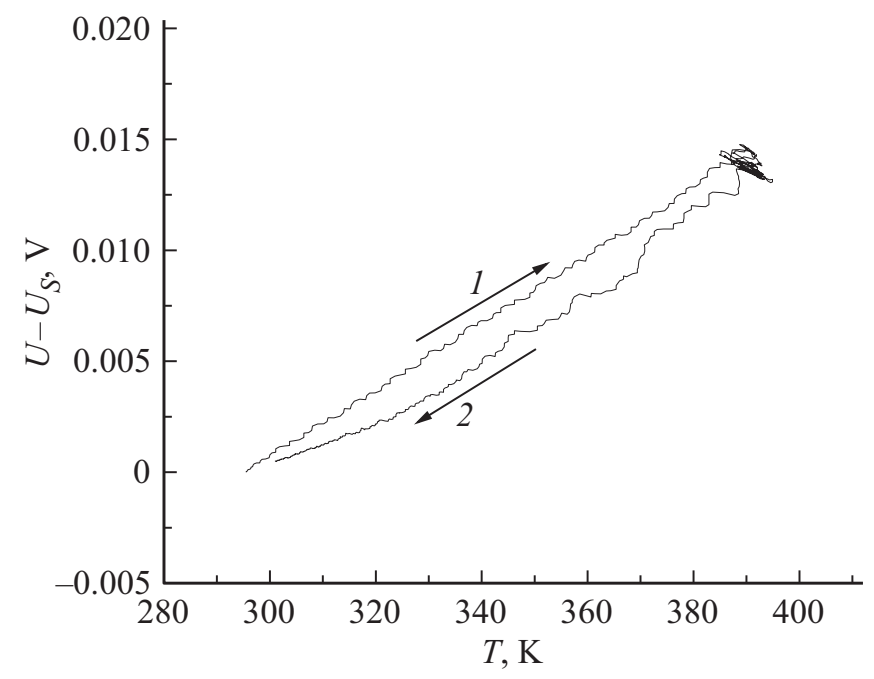

Рис. 3. Температурные зависимости генерируемого за счет термовольтаического эффекта в структуре на основе $\mathrm{PbTe}$ напряжения. 1 - нагревание, 2 - охлаждение.

(медная пластина 3) и верхнего (точечного 4) контактов с помощью мультиметра RIGOL DM3061 (D3). Температуры у контактов измерялись термопарами $T 1$ и $T 3$ и регистрировались цифровым термометром Voltcraft K204 (D4). Управление экспериментом и регистрация данных осуществлялись программой, созданной в среде LabVIEW, на ЭВM (PC). 
На рис. 2 представлены кривые, полученные в эксперименте по измерению термовольтаического эффекта в гетероструктуре на основе $\mathrm{PbTe}$. Из этого рисунка следует, что сигнал от термовольтаического эффекта (до $\sim 0.015 \mathrm{~V}$ ) существенно превосходит по величине сигнал от эффекта Зеебека (до $\sim 0.001 \mathrm{~V}$ ).

На рис. 3 представлена температурная зависимость сигнала от термовольтаического эффекта, полученная из данных рис. 2: зависимость $\left(U-U_{S}\right)$ от $T$. Наблюдается близкая к линейной зависимость сигнала от температуры. При повышении температуры до $732 \mathrm{~K}$ была достигнута величина генерируемого напряжения $0.11 \mathrm{~V}$.

Таким образом, нами обнаружен термовольтаический эффект в типичном термоэлектрическом материале для среднетемпературного интервала. Достаточно большие величины, полученные за счет термовольтаического эффекта напряжения $(0.015 \mathrm{~V}$ при $T=390 \mathrm{~K}$ и $0.11 \mathrm{~V}$ при $732 \mathrm{~K}$ ), дают основание продолжать исследования с целью выявления возможности применения РbTe для преобразования тепловой энергии в электрическую на основе термовольтаического эффекта в среднетемпературном интервале.

\section{Конфликт интересов}

Авторы заявляют, что у них нет конфликта интересов.

\section{Список литературы}

[1] Каминский В.В., Соловьёв С.М. // ФТТ. 2001. Т. 43. В. 3. C. 423-426.

[2] Пронин И.А., Аверин И.А., Божинова А.С., Георгиева А.Ц., Димитров Д.Ц., Карманов А.А., Мошников В.А., Папазова К.И., Теруков Е.И., Якушова Н.Д. // Письма в ЖТФ. 2015. T. 41. B. 19. С. 23-29.

[3] Саидов А.С., Лейдерман А.Ю., Каршиев А.Б. // Письма в ЖТФ. 2016. Т. 42. В. 14. С. 21-27.

[4] Егоров В.М., Каминский В.В., Казанин М.М., Соловьев С.М., Голубков А.В. // Письма в ЖТФ. 2013. Т. 39. B. 14. C. $57-61$.

[5] Снапян А.Х., Гречко Н.И., Ковырзин А.В., Судак Н.М., Инглизян П.Н. Кольцевой термоэлектрический модуль на основе теллурида свинца // XIII Межгосударственный семинар „Термоэлектрики и их применения“. СПб.: ФТИ им. А.Ф. Иоффе, 2012.

http://www.ioffe.ru/Thermolab/seminar2012/oral/28o_Snapian.pdf 